Максимова Анастасия Сергеевна канд. экон. наук, ФГБУН

«Институт социально-политических исследований Российской академии наук», г. Москва

e-mail:lubijizn@yandex.ru

Милехин Андрей Владимирович д-р. социол. наук, канд. психол. наук, ФГБОУ ВО «Московский государственный университет им. М.В. Ломоносова», г. Москва e-mail:Andrey@Milekhin.ru
Maksimova Anastasiya Candidate of Economics Sciences, Institute of Socio-Political Research of Russian Academy of Sciences, Moscow

e-mail:lubijizn@yandex.ru

\section{Milekhin Andrey}

Doctor of Sociological Sciences, Candidate of Psychological Sciences, Lomonosov Moscow State University, Moscow

e-mail: Andrey@Milekhin.ru

\section{СОЦИОЛОГИЧЕСКИЙ МОНИТОРИНГ КАК ИНСТРУМЕНТ ДИАГНОСТИКИ СОЦИАЛЬНОЙ НАПРЯЖЕННОСТИ В МИГРАЦИОННО ПРИВЛЕКАТЕЛЬНЫХ РЕГИОНАХ}

\begin{abstract}
Аннотация. Рассмотрено применение социологического мониторинга для анализа социальной напряженности и предупреждения этнических конфликтов в наиболее привлекательных для мигрантов регионах России. Описаны виды сочиальных противоречий, возникновение которых может быть обусловлено высокой привлекательностью территории для мигрантов, как иностранных, так и внутренних, и может спровоцировать возникновение и нарастание соииальной напряженности. Рассмотрень основные детерминанты соичильной напряженности в миграционно привлекательных регионах. Отмечено, что сочиальная напряженность обусловлена не только этническими и этнокультурными особенностями мигрантов, не характерными для населения принимающего сообщества, но в то же время, экономическими противоречиями между интересами местного населения и интересами мигрантов.

Ключевые слова: социальная напряженность, интеграция мигрантов, этническая социализачия, социологический мониторинг, мониторинг социальной напряженности.

\section{SOCIOLOGICAL MONITORING AS A TOOL FOR SOCIAL TENSION MEASUREMENT IN THE REGIONS MOST ATTRACTIVE FOR MIGRANTS}

\begin{abstract}
The application of social monitoring for the analysis of social tensions and ethnic conflicts prevention in the Russian regions that are most attractive for migrants are considered. The types of social contradictions, the occurrence of which may be due to the high attractiveness of the territory for migrants, both foreign and domestic, and provoke the emergence and increase of social tensions, - are described. The main determinants of social tension in the most attractive regions for migration are considered. It is noted that social tension is determined not only by ethnic and ethno-cultural characteristics of migrants, not typical for the population of the receiving community, but also by the contradictions between the economic interests of the local population and the economic interests of migrants.

Keywords: social tension, integration of migrants, ethnic socialization, sociological monitoring, monitoring of social tension.
\end{abstract}

Диалектика сложноорганизованной социальной системы предполагает наличие противоречивого сочетания устойчивости и изменчивости (развития). Основой развития (по диалектическому закону) является нарастание противоречий. Только с позиций диалектики можно понять сложный, полный противоречий путь становления объективной истины, связь устойчивого и изменчивого [8]. Согласно принципу ле Шателье, целостная система, т. е. система «подвижного равновесия», в рамках внутреннего регулирования сравнивает текущее состояние со стационарным и при отклонении передает сигнал о необходимости вернуться в равновесное состояние.

Социальная напряженность является флуктуацией от равновесного состояния социальной стабильности. Выходом из состояния социальной напряженности являются либо конфликт, либо компромисс, либо его стагнация, которая пролонгирует данное состояние, и в конечном итоге, все же завершается конфликтом или компромиссом. «Социальный конфликт - особая форма отношений между людьми и группами людей, для которой характерна несовместимость интересов, ценностей и устремлений, взаимная враждебность сторон, агрессивные и насильственные намерения или действия по отношению друг к другу» [1, с. 14]. Конфликт, в отличие от недоразумения или других видов соперничества, имеет «разрушительное воздействие на ту или иную социальную структуру или систему, в пределах которой он формируется» [1, с. 14].

Факторы и причины социальной напряженности, как правило, сводятся к невозможности удовлетворения тех или иных потребностей части населения. Однако, наряду с этим, при условии отсутствия ограничения

(C) Максимова А.С., Милехин А.В., 2018 
на удовлетворение потребностей, необходимо рассматривать в качестве факторов возникновения социальной напряженности: «невозможность реализовать интересы той или иной группы (интересы самовыражения и самоутверждения) или стремление утвердить в социальной среде те или иные ценности», а также комбинацию или чередование вышеназванных факторов [3, с. 25]. В перечисленных случаях социальная напряженность нарастает постепенно. Мгновенный всплеск социальной напряженности наблюдается в том случае, когда действия, предпринимаемые властями, либо некоторой группой населения, ущемляют интересы другой социальной группы, что практически сразу переходит в стадию социального конфликта. Как, например, это было в 2015 г. при введении обязательных платежей для грузового транспорта при проезде по федеральным трассам, что спровоцировало массовые и затяжные протестные выступления владельцев и водителей.

Миграция в контексте социальных конфликтов может быть рассмотрена с двух сторон: в качестве источника социальной напряженности, а, позднее - конфликтогена, и в качестве способа действия населения при общественно-негативных настроениях, выражающегося в виде массового оттока населения - эмиграции. Если масштабы последней целесообразно рассматривать в рамках проблем потери человеческого капитала страны выхода мигранта, поскольку выезжает наиболее мобильное, образованное, зачастую успешное в бизнес- или научной сфере население, то масштабы миграции как конфликтогена следует рассматривать в контексте проблем национальной безопасности.

Социальная напряженность характеризуется, прежде всего, распространением настроений неудовлетворенности существующей ситуацией в той или иной жизненно важной сфере, утратой доверия к властям, снижением авторитета власти, появлением ощущения опасности [9]. Способами выражения социальной напряженности являются не только общественные настроения, но и массовые действия: митинги, открытые конфликты, которые могут оборачиваться существенными материальными потерями и потерями человеческих ресурсов, а также нести прямые жертвы.

Ярким примером служит конфликт в Кондопоге 2006 г. (на тот момент в городе проживало около 40 тыс. жителей), когда проблемы микросоциума переросли в локальный конфликт. В данном случае, конфликтная ситуация сложилась на фоне большого числа внутрироссийских мигрантов, а поводом к конфликту стало убийство выходцами северо-кавказских республик нескольких человек. Это привело к масштабной агитации населения митинговать против самих переселенцев с Кавказа, а также против властей. По мнению местного населения, участвующего в беспорядках, небольшая, но сплоченная группа жителей Северного Кавказа, преимущественно состоящая из чеченцев, «не считались с принятыми среди представителей коренного населения нормами и правилами поведения, унижали их достоинство и угрожали здоровью» [2, с. 9]. По оценкам исследований, проведенных уже после стихания активной фазы конфликта, 38,1 \% опрошенных готовы были принять участие в акциях протеста снова [2]. Наблюдалось форсирование событий в средств массовой информации (далее - СМИ), в частности, сети Интернет: большое количество негативно окрашенного контента, посвященного развитию событий, охватившего все сегменты виртуального общения, породили огромную волну активных дискуссий.

Выделяют следующие виды социальной напряженности, в соответствии с источником: инициированная, культивированная, спровоцированная социальная напряженность; стихийная, неконтролируемая, произвольно возникающая; социальная напряженность, комбинирующая в себе элементы первого и второго вида естественно-искусственная [3]. Применительно к ситуации с мигрантами, примером социальной напряженности первого типа является формирование негативного образа мигранта в общественном сознании под воздействием СМИ. Примером естественно возникающей социальной напряженности можно считать нарастание противоречий вследствие конкуренции на рынке труда между мигрантами и представителями принимающего сообщества.

Социальный конфликт, возникающий по причинам, связанным с миграцией и мигрантами, в миграционно привлекательных регионах может иметь форму социально-экономического, социально-политического или этнического (этнокультурного) конфликта (рис. 1). Конфликтогенами в каждом из этих случаев выступают: нарушение баланса экономических интересов между мигрантами и членами принимающего сообщества, главным образом на рынке труда; политическая борьба (борьба за власть, за изменение территориальных границ); дисбаланс учета интересов одной из сторон в части обеспечения совокупности гражданских прав; дисбаланс учета интересов одной из сторон в части распространения этнокультурных или этнолингвистических признаков [6]. В последнем случае чаще всего встречается форма субъективного восприятия местным населения ущемления их прав в виде широкого распространения культурных или 
языковых признаков, присущих пришлому населению. Либо недостаточное с точки зрения представителей этнического меньшинства, использование его языка и культурных символов в общественной жизни [4]. В то же время социальная напряженность может сама выступать фактором усиления преступности, как способа проявления неудовлетворенности текущим состоянием сферы общественной жизни.

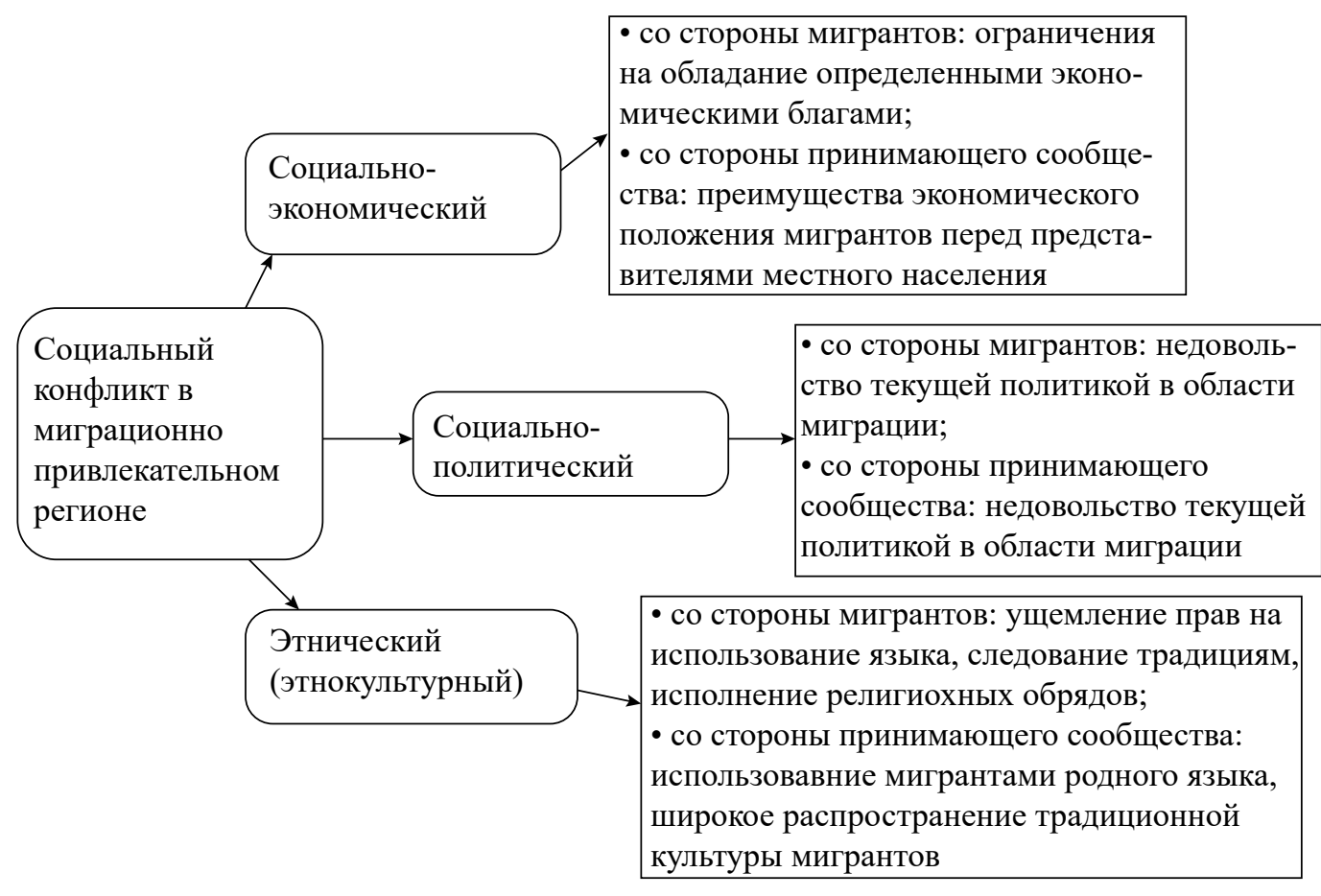

Составлено авторами по материалам исследования

Рис. 1. Соответствие видов и факторов социального конфликта, возникающего по причинам, связанным с миграцией и мигрантами

Нарастающие в настоящее время темпы интеграционных процессов Евразийского экономического союза (далее - ЕАЭС), способствующих возникновению и расширению миграционного коридора между Россией и соседними в прошлом советскими республиками: Казахстаном, Узбекистаном, Кыргызстаном и Таджикистаном, влекут за собой ряд экономических, демографических и социальных проблем. Упрощение порядка въезда, пребывания и работы на территории ЕАЭС граждан другого государства-члена способствует сохранению численности мигрантов, прибывающих для постоянного проживания в Россию на уровне около 50 тыс. чел. в год из Таджикистана, 60-70 тыс. чел. в год из Казахстана, 25-30 тыс. чел. в год из Кыргызстана. Отмечается увеличение доли украинских мигрантов в российском миграционного сальдо - стремительный рост мигрантов наблюдается в 2014-2015 гг. - среднегодовые темпы прироста к предыдущему году составили 160 \% и 50 \% соответственно, в 2016 г. рост миграционного сальдо замедлился как за счет снижения прибывших, так и за счет увеличения численности выбывших по сравнению с предыдущим годом. В целом, годовое сальдо миграции России с зарубежными странами в 2016 г. составило, по данным российской статистики, около 262 тыс. чел., а 97,5 \% общего миграционного прироста приходилось на страны СНГ. Таким образом, в рейтинге миграционных партнеров России страны СНГ по-прежнему занимают наиболее высокие позиции по показателям сальдо миграции и миграционного оборота.

Однако миграция на постоянное место жительства по объемам потоков уступает трудовой миграции. По оценкам экспертов, численность недокументированных трудовых мигрантов, ежегодно находящихся на территории России, составляет около 3 млн. [5]. Поскольку законодательная база трудоустройства мигрантов из стран ЕАЭС в России в настоящее время является довольно либеральной, большинство граждан государствчленов ведут трудовую деятельность на территории России, оплатив патент на определенный срок, предпочитая его разрешению на работу. Подобная система не позволяет вести всеохватывающий учет численности иностранных трудовых мигрантов, находящихся на территории России. Поэтому данные оценки весьма условны. В том 
числе это происходит по причине высокой динамичности самой природы процесса миграции - постоянных перемещений мигрантов: зачастую они пересекают государственную границу по несколько раз в год.

В расчете на 1000 человек, населения, постоянно проживающего на территории России, ежегодно приходится 4 въезжающих на территорию России мигранта, или около 2 человек миграционного прироста. Миграционно привлекательными для иностранных граждан являются: Московская область, Краснодарский край, Новосибирская область и Тюменская область (по итогам 2016 г.), в каждом из которых миграционный прирост составил от 8 до 10 тыс. человек в год [11]. Привлекательность российских регионов для иностранных мигрантов существенно трансформировалась за последние годы. В 2014 г. в числе миграционно привлекательных были г. Москва, Калужская обл. А еще годом ранее первое место по миграционному приросту занимал г. СанктПетербург, имеющий в настоящее время отрицательное сальдо миграции. В 2010 г., до смены принципов учета мигрантов, привлекательными традиционно были г. Москва, Московская область и г. Санкт-Петербург. После изменения методологии, когда в числе постоянных мигрантов стали учитываться лица, прибывшие на срок 9 месяцев и более, в число миграционно привлекательных регионов вошли Тюменская и Новосибирская области.

Таблица 1

\section{Миграционный прирост регионов России, наиболее привлекательных для переселенцев, вследствие международной миграции}

\begin{tabular}{|l|l|l|l|l|l|}
\hline \multirow{2}{*}{\multicolumn{1}{|c|}{ Регион }} & \multicolumn{5}{|c|}{ Миграционный прирост, чел. } \\
\cline { 2 - 6 } & \multicolumn{1}{|c|}{$\mathbf{2 0 1 1}$ г. } & \multicolumn{2}{|c|}{$\mathbf{2 0 1 3}$ г. } & \multicolumn{1}{c|}{$\mathbf{2 0 1 5}$ г. } & \multicolumn{2}{c|}{$\mathbf{2 0 1 6}$ г. } \\
\hline Московская область & 23243 & 16504 & 17021 & 20785 & 20409 \\
Краснодарский край & 15334 & 14151 & 13138 & 16068 & 13699 \\
Тюменская область & 21491 & 14155 & 13546 & 12143 & 16962 \\
Новосибирская область & 13041 & 8822 & 7785 & 8660 & 12666 \\
Курская область & 3399 & 5264 & 4989 & 10315 & 10415 \\
\hline
\end{tabular}

*Регионы отсортированы по мере уменьшения величины миграционного прироста в 2016 г.

Источник: [11]

Указанные регионы, сталкивающиеся более других с проблемами, порождаемыми миграцией, острее нуждаются в практике ведения мониторинга социальной напряженности. Однако, это не означает, что его не должно быть в других регионах, поскольку социальный конфликт может быть спровоцирован трудовой миграцией иностранной рабочей силы, а также внутренней миграцией населения России, отличающегося этнической идентичностью от населения принимающего сообщества. Конфликт может быть вызван и острыми противоречиями между незначительной по численности группой мигрантов и местным сообществом, если имеют место факторы возникновения социального конфликта и обострения социального противоречия.

Одним из факторов обострения социального противоречия выступает трансформация временной трудовой миграции в постоянную: многие бывшие трудовые мигранты становятся постоянными жителями России, получают гражданство. Это влечет за собой не только дополнительную нагрузку на сферу социального обеспечения принимающей страны, которой в данном случае выступает Россия, но и порождает другую острую проблему: проблему неприятия местным населением. К примеру, мигранты, недавно ставшие российскими гражданами, обеспечиваются всеми видами социальной поддержки: получают социальные пособия, льготный проезд, льготные условия ипотечного кредитования. Местными жителями это не всегда воспринимается положительно. Как известно, естественное воспроизводство населения в странах СНГ гораздо выше, чем в России, поэтому рождаемость среди иммигрантов значительно выше, чем среди местного населения. Репродуктивное поведение мигрантов, приехавших в Россию и получивших впоследствии гражданство, хотя и адаптируется под влиянием иной, менее традиционной, социальной реальности, но в то же время, продолжает обладать некоторыми присущими ему ранее чертами. Склонность к исполнению основных социальных ролей, не позволяет придерживаться малодетной модели рождаемости или вовсе отказаться от рождения детей. При этом, переселяется, главным образом, население в трудоспособном и фертильном (для женщин) возрасте. 
Реальные масштабы иммиграционного потока не могут быть оценены достоверно, а оценки экспертов в разы превосходят официальные данные, при этом в стране полностью отсутствует единая адаптационная стратегия и конкретные меры по ее реализации. В подобных условиях диагностика социальной напряженности имеет еще более значимый характер, поскольку существует необходимость оценки реакции местного населения на миграционные процессы.

По данным опросов «ВЦИОМ-Спутник» за 2017 г. только 3 \% россиян источником основной террористической угрозы считают мигрантов. При этом, только $1 \%$ опрошенных видят в мигрантах из Средней Азии причину отсутствия единения русского народа. Среди наиболее важных проблем в стране, существующих в настоящее время, увеличение количества мигрантов из Средней Азии назвали не больше 1 \% [10]. Спад общественного протестного потенциала был отмечен в III квартале 2014 г., когда общий индекс достиг 24, а возможность массовых выступлений отметили 16 \% опрошенных. По итогам февраля 2018 г. индекс протестного потенциала сохраняет значения, присущие предыдущим годам в целом, однако, с начала 2018 г. протестные настроения населения постепенно снижаются.

«Сеть этнологического мониторинга и раннего предупреждения конфликтов» (EAWARN) представляет собой экспертный опрос. В 1996 г. была разработана система условных индикаторов конфликтности, состоящая из 7 категорий: среда и ресурсы; демография и миграция; власть, государство и политика; экономика и социальная сфера; культура, образование, информация; внешние условия [7]. В рамках демографической категории индикаторами выступают: расселение населения (динамика численности, этнические пропорции, степень и динамика урбанизации), смешанные браки и разводимость, естественное движение населения, территориальное движение населения.

В условиях масштабного привлечения иностранных, преимущественно трудовых, мигрантов в Россию, необходимо внедрение системы мониторинга степени остроты социальной напряженности как первоочередной ступени предотвращения социальных конфликтов и своевременного выявления их предпосылок. Подобная система должна включать модули сбора и оценки информации, ориентированные на выявление экономических, политических, и этнокультурных явных или латентных противоречий между мигрантами и принимающим сообществом. В ходе построения методологических основ мониторинга социальной напряженности, в первую очередь, необходимо остановиться на проработке теоретических основ возникающей проблемы социальной напряженности и связанных с ней этнических и этноконфессиональных конфликтов; вторым этапом станет разработка методологических основ мониторинга. Для проектирования инструментов измерения социальной напряженности необходимо понимание самой природы социальной напряженности и социальных конфликтов, прежде всего, этнически окрашенных.

Методика оценки социальной напряженности предполагает не только разработку инструментария сбора информации, но и оценочной базы, в рамках который должны быть разработаны индикаторы и шкалы их оценки. Для предотвращения конфликтов и снижения социальной напряженности необходимо учитывать ожидания, потребности и интересы обеих групп: мигрантов и представителей принимающего сообщества, а также диагностировать несоответствие между ожиданиями и требованиями с одной стороны и реальным положением дел - с другой.

Выявление состояния социальной системы - главная задача и основной вектор мониторинга социальной напряженности (рис. 2). Второй вектор исследования должен охватывать динамику уровня социальной напряженности и его прогнозирование, с оценкой риска возникновения социального конфликта. Третий вектор направлен на выявление региональных различий уровня социальной напряженности. Данные различия объясняются, прежде всего, миграционной привлекательностью региона, а, соответственно, и численностью мигрантов, в совокупности с социально-демографическими характеристиками постоянного населения этого региона в континууме наблюдающейся экономической и политической реальности. Уровень социальной напряженности и близость социальной системы к пределу устойчивости зависит не только и не столько от численности мигрантов, сколько от состояния экономики и дисбаланса рынка труда, который должен обладать достаточной емкостью для принятия дополнительной рабочей силы. Важную роль играет явная и латентная конкуренция на рынке труда между мигрантами (как временными трудовыми мигрантами, так и постоянными) с одной стороны и местными жителями - с другой. В случае достаточного предложения на рынке труда, работодатель отдает предпочтение более дешевой, и, как правило, менее квалифицированной рабочей силе, которой являются иностранные трудовые мигранты. 


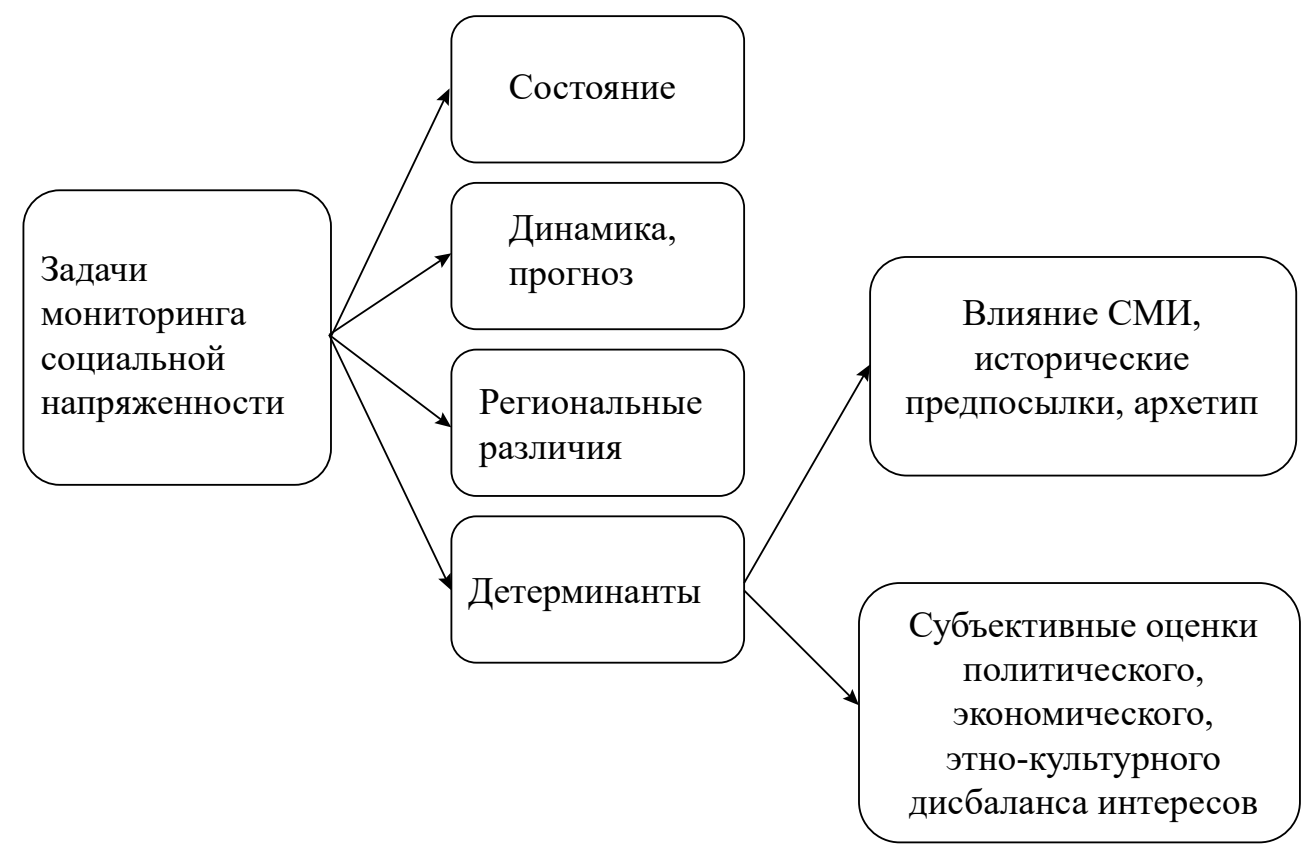

Составлено авторами по материалам исследования

Рис. 2. Основные задачи социологического мониторинга социальной напряженности

Четвертый вектор исследования посвящен выявлению основных детерминант социальной напряженности. Внимания заслуживают, на наш взгляд, две важных группы факторов: факторы-причины (экономические, политические, этнокультурные) и факторы-катализаторы (исторические предпосылки, влияние СМИ на формирование образа мигрантов как угрозы национальной безопасности, негативно окрашенные слухи, мнения, настроения). Первопричинными могут выступать как одни, так и другие.

Воспроизводимая в СМИ информация не всегда имеет под собой реальные статистические основания и зачастую основана на частном опыте. Как правило, репортажи и статьи освещают только негативно окрашенные ситуации, в которые вовлечены мигранты, а примеры демонстрации позитивного опыта встречаются крайне редко, и относятся к мигрантам из более развитых стран, либо стран Африки и Латинской Америки.

Проведению мониторинга должна предшествовать оценка исторических предпосылок возникновения социальных конфликтов, и предыдущий опыт их разрешения, что поможет описать конфликтное поле.

Если уровень социальной напряженности может быть оценен благодаря анализу первичных данных источников информации, то динамика и региональные различия - направления исследования, которые могут быть реализованы на основе накопления первичной информации по итогам предыдущих этапов исследования в случае динамики, и на основе сравнительного анализа - в случае региональных различий. Анализ детерминант социальной напряженности основывается на комбинации данных первичной информации и применения математико-статистических методов ее обработки.

С точки зрения инструментария мониторинга, необходимо рассматривать в качестве основных источников информации: данные анкетного опроса, либо данные глубинных интервью (в зависимости от спецификации задач и территориальных различий), экспертные мнения, контент-анализ материалов сети Интернет.

Предлагаемая программа мониторинга социальной напряженности для миграционно привлекательных регионов будет включать этапы, оценивающие следующие факторы.

1. Установление иерархии социально-экономических, политических, культурно-нравственных и экологоклиматических проблем страны в целом и конкретного региона проживания респондентов.

2. Установление иерархии проблем самих респондентов (уровень жизни, проблемы рынка труда, обеспеченность основными благами и услугами, реализация прав и свобод, неуверенность в завтрашнем дне, социальная незащищенность, личные и семейные проблемы). 
3. Выявление степени доверия населения различным политическим институтам и оценок основных политических и общественных лидеров; определение отношения россиян к происходящим политическим событиям.

4. Определение отношения респондентов к проживающим в России иммигрантам и трудовым мигрантам, угроз и рисков, связанных с ними (выявление проблем, возникающих, по мнению респондентов, в регионе и стране по причинам, связанным с миграцией и мигрантами; наличие личного опыта негативного и позитивного взаимодействия с мигрантами; оценка видов и степени опасности, исходящей от мигрантов как лично для респондента, так и для страны и региона в целом; оценка возможных положительных эффектов от миграции для страны и региона в целом, и вероятных преимуществ от взаимодействия с мигрантами - лично для респондента).

5. Выявление наиболее эффективных по воздействию на образ мигранта источников информации (степень использования различных источников информации; оценка контента о миграции и мигрантах, демонстрируемого в СМИ; выявление СМИ, имеющих наибольшее влияние на формирование антимиграционных настроений).

6. Выявление степени остроты социальной напряженности (оценка респондентами возможности возникновения конфликтов; допустимые, по мнению респондентов, формы протеста и защиты своих прав; намерения респондентов принимать участие в данных формах протеста; стадия социальной напряженности: возникновение предпосылок, становление, развертывание, закрепление, выдвижение требований, взаимодействие сторон по поводу требований)

7. Оценка религиозно-культурной среды населения принимающего сообщества (наличие групповой идеологии; уровень толерантности; конфессиональный состав; религиозная «инфраструктура» и возможности совершать обряды; распространенность языков) и распространенности культуры и языка больших этнических групп мигрантов в принимающем сообществе.

8. Социально-демографические и социально-экономические характеристики респондентов.

В соответствии с выделенными этапами для проведения и оценки данных социального мониторинга должна быть сформирована система индикаторов, включающая:

- иерархию проблем региона (по субъективным оценкам);

- иерархию собственных проблем населения региона;

- состояние социального равновесия в регионе, выражающегося через распространенность и глубину социальной напряженности;

- социальную и протестную активность населения региона.

О развитии определенного градуса социальной напряженности в обществе свидетельствуют следующие показатели:

- наличие большой доли респондентов, давших неудовлетворительную оценку собственному уровню жизни, положению на рынке труда, положению в обществе, возможностям для реализации своих планов, заявляющих об ущемлении их прав;

- наличие большой группы респондентов, давших неудовлетворительную оценку действующим политическим институтам, власти, политическим решениям и мерам, состоянию экономики региона;

- наличие большой группы респондентов, у которых сформировано негативное отношение к прибывающим в регион мигрантам, и которые связывают собственные проблемы и проблемы региона именно с миграцией;

- высокие показатели общей готовности к протесту, особенно в его категоричных формах.

Мониторинг социальной напряженности, позволяющий получить удовлетворяющие требованиям точности и объективности оценки противоречий социального климата и предупредить вероятные социальные конфликты, дает широкие возможности осуществления эффективного социального управления. Практическое использование получаемых в ходе мониторинга данных позволяет планировать, разрабатывать стратегии и меры достижения целей социального развития. Для миграционно привлекательных регионов использование мониторинга социальной напряженности в контексте решения задач социального управления на всех этапах его реализации представляется крайне необходимым.

\section{Библиографический список}

1. Авксентьев, В. А. Этническая конфликтология .- В 2 ч.- Ч. 1. Ставрополь: Изд-во СГУ, 1996.- 154 с.

2. Григорьев, М. Кондопога: что это было / М. Григорьев. -М.: Издательство «Европа», 2007. - 216 с. 
3. Иванов, О. И. Социальная напряженность и социальный конфликт // Вестник Санкт-Петербургского университета. Серия 6. - 2005.- № 3.-С. 24-30.

4. Крысько, В. Г. Этническая психология . - 6-е изд. - М.: Издательский центр «Академия», 2011. - 320 с.

5. Рязанцев, С. В. Вклад трудовой миграции в экономику России: методы оценки и результаты // Гуманитарные науки. Вестник Финансового университета. - 2016. - № 2 (22).- С. 16-28.

6. Социальные факторы межэтнической напряженности в России: монография / отв. ред. Ю. Б. Епихина, М. Ф. Черныш. М.: ФНИСЦ РАН, 2017. - $336 \mathrm{c}$.

7. Тишков, В. А. Измерение конфликта. Методика и результаты этноконфессионального мониторинга Сети EAWARN в 2003 году / В. А. Тишков, В. В. Степанов. - М.: ИЭА РАН, 2004. - 322 с.

8. Философский словарь / Под ред. М. М. Розенталя. Изд. 3-е. - М. : Политиздат, 1972. - 496 с.

9. Чернобродов, Е. Р. Факторы, определяющие социальную напряженность в Хабаровском крае // Вестник ДВЮИ МВД России. - 2013. -№ 2 (25).- С. 78-83.

10. База результатов опросов россиян «Спутник» [Электронный ресурс]. - Режим доступа: https://wciom.ru/database/baza_ rezultatov_sputnik/ (дата обращения: 12.02.2018).

11. Официальный сайт государственной статистики России [Электронный ресурс]. - Режим доступа: www.gks.ru (дата обращения: 26.02.2018).

\section{References}

1. Avksent'ev, V. A. Etnicheskaya konfliktologiya [Ethnic conflictology]. Part 1. Stavropol: SGU, 1996, 154 p.

2. Grigor'ev M. Kondopoga: chto jeto bylo [Kondopoga: what was it]. M.: Europe, 2007, 216 p.

3. Ivanov O. I. Social'naja naprjazhennost' i social'nyj konflikt [Social tensions and social conflict]. Bulletin of St. Petersburg University. Seriya 6 [Vestnik Sankt-Peterburgskogo universiteta.Series 6], 2005, I. 3, pp. 24-30.

4. Kryis'ko V. G. Jetnicheskaja psihologija [Ethnic psychology]. 6-th Edition. M.: Academiya, 2011, 320 p.

5. Ryazantcev S. V. Vklad trudovoj migracii v jekonomiku Rossii: metody ocenki i rezul'taty [Contribution of labour migration to the Russian economy: evaluation methods and results]. Gumanitarnye nauki. Vestnik Finansovogo universiteta [Humanities. The Bulletin of the Financial University], 2016, I. 2 (22), pp. 16-28.

6. Social'nye faktory mezhjetnicheskoj naprjazhennosti v Rossii [Social factors of interethnic tension in Russia]. Editors U. B. Uepihina, M. F. Chernush. M.: FNISC RAS, 2017, 336 p.

7. Tishkov V. A., Stepanov V. V. Izmerenie konflikta. Metodika i rezul'taty jetnokonfessional'nogo monitoringa Seti EAWARN $\mathrm{v} 2003$ godu [The dimension of the conflict. The methodology and results of ethnic and religious monitoring Network EAWARN in 2003]. M.: IEA RAS, 2004, 322 p.

8. Filosofskij slovar' [Philosophical dictionary]. Editor M.M. Rozental'. 3-d Edition. M.: Politizdat, 1972, 496 p.

9. Chernobrodov E. R. Faktory, opredeljajushhie social'nuju naprjazhennost' v Habarovskom krae [Factors determining social tension in the Khabarovsk territory]. Vestnik DVJuI MVD Rossii [Bulletin of DUI of the MIA of Russia], 2013, I. 2 (25), pp. 78-83.

10. Baza rezul'tatov oprosov rossijan «Sputnik» [Base of survey results of Russians «Sputnik»] Available at: https://wciom.ru/ database/baza_rezultatov_sputnik/(accessed 12.02.2018).

11. Oficial'nyj sajt gosudarstvennoj statistiki Rossii [Official website of state statistics of Russia] Available at: www.gks.ru (accessed 26.02.2018). 